\title{
SISTEM KEAMANAN JAIL BASH UNTUK MENGAMANKAN AKUN LEGAL DARI KEJAHATAN INTERNET MENGGUNAKAN THC- HYDRA
}

\author{
Cakra Aminuddin Hamka, Haruno Sajati, Yuliani Indrianingsih \\ Teknik Informatika \\ Sekolah Tinggi Teknologi Adisutjipto Yogyakarta \\ informatika@stta.ac.id
}

\begin{abstract}
Along with the developmentof current technology, making technologyis very important in today's life. Security level digital data has become more vulnerable to exploitation, the problem arises when an information technology device was attacked by people who do not want to take a responsible and important data illegally, so the administrator must act quickly to secure important data. Making a data security technology on the internet is very important information. Limitations administrator underlying the creation of a system that is able to detect and defense systems against such attacks is automation, so that it can be applied to data security. The system is built to prevent attacks on computer networks with more specificon THC-Hydra. This system will analyze the number of errors in the log into the database, and if the error exceeds the tolerance rules are made by the administrator. If the error is more than 3 times in one minute, then with automation, the system will create a rule that can imprison users who do not have such access, and access to the prison in the illegaluser can not perform such activities on legal access and access to activities conducted illegal user can be recorded on a file and jail.txt. Sounder any circumstances and not in supervising administrator, the security of other user data will be safe and can not be retrieved or viewed by a user of illegal access.
\end{abstract}

Keywords: Automation, THC-Hydra, the illegal user access, legal user access.

\section{Pendahuluan}

Keamanan jaringan komputer sebagai bagian dari sebuah sistem informasi adalah sangat penting untuk menjaga validalitas dan integritas data serta menjamin ketersediaan layanan bagi pengguna dan administrator. Sistem deteksi penyusupan jaringan internet saat ini umunya mampu mendeteksi berbagai jenis serangan, namun tidak mampu mengambil tindakan lebih lanjut, dan tidak memiliki kemanfaatan ilmu pengetahuan. Dalam penelitian ini adalah dengan membangun aplikasi yang dapat melakukan kegiatan auto respon terhadap aktifitas penyusup dengan menggunakan bahasa pemrograman $p h p$, dan dapat merekam segala aktifitas yang dilakukan akses user ilegal dengan menggunakan bahasa pemrograman $\mathrm{C}^{++}$. Dan tidak hanya itu, penelitian ini dapat melakukan proses recovery data. Dikarenakan saat ini serangan sangat beraneka-ragam, salah satunya dengan menggunakan THC-Hydra, maka hal ini sangat penting untuk dalam proses penelitian ini, maka munculah sebuah ide untuk memberikan sebuah sistem penjara untuk mengamankan akun, dan di dalam penjara tersebut, kegiatan akses user ilegal tidak dapat terlaksana dan kegiatan tersebut akan direkam oleh sistem tersebut. 


\section{Metodologi}

\subsection{Shell}

Mahardika (2003), shell adalah program penghubung user dengan kernel sistem operasi adalah program shell tersebut. Setiap perintah yang inputkan oleh user akan diterjemahkan oleh shell kemudian dikirimkan hasilnya ke kernel dan kernel tersebut melakukan operasi yang diminta oleh user. Gambaran saat shell menjalankan program, yang tetap memanggil sistem call fork dan exec untuk menjalankan program yang diinginkan $u$ ser.

\subsection{Bash}

Bash adalah shell, untuk penerjemah bahasa perintah, yang terdapat pada sistem operasi GNU, misalnya Linux, BSD, SCO (paket Skunkware). Bash kompatibel dengan shell sh dan kemampuan atau karakteristik yang dimiliki oleh Korn Shell $(k s h)$ dan $C$ Shell (Csh). Hal ini menjadi implementasi dari IEEEPOSIX Shell dan bagian dari IEEEPOSIX spesifikasi (Standar IEEE 1003.1). Bash melakukan perbaikan fungsional selama sh untuk digunakan baik interaktif dan pemrograman. Bash sangat portabel saat melakukan penetrasi di hampir setiap versi Unix, dan didukung untuk MS-DOS, OS/2, dan Windows (Susanto, 2004).

\subsection{Konsep Sistem User di Linux}

Sistem user pada LINUX harus terdaftar pada sistem LINUX secara otomatis diberikan sebuah direktori kerja sesuai nama user yang terdaftar. Sistem Linux selalu merekam user baru yang ditambahkan oleh super user. Pada saat menambahkan user baru, setiap user akan selalu diberikan sebuah direktori kerja pada/home. Pada direktori home akan terdapat direktori kerja masing-masing user yang telah terdaftar menggunakan nama standard oleh usernya. Sebagai keamanan, user biasa tidak akan dapat mengakses direktori lain atau direktori kerja user lainnya. User yang dapat mengakses direktori yang bukan miliknya apabila telah diberi hak akses pada super user (Nugroho, 2005).

\subsection{THC-Hydra}

THC Hydra adalah suatu program perangkat lunak untuk mempenetrasi password sebuah user atau pengguna pada sistem, dalam penerapannya Hydra sangat memungkinkan tingkat keberhasilannya apabila suatu password tingkat rendah, dikarenakan Hydra melakukan kombinasi yang umum dan secara terus menerus hingga berhasil. Penetrasi Hydra sangat mudah, hanya mengetikkan suatu script untuk menuju sebuah user dan aplikasi tersebut dapat berjalan. Program ini mempunyai kemudahan untuk bagaimana mendapatkan akses tidak sah dari remote ke sistem. 


\subsection{Analisa Sistem}

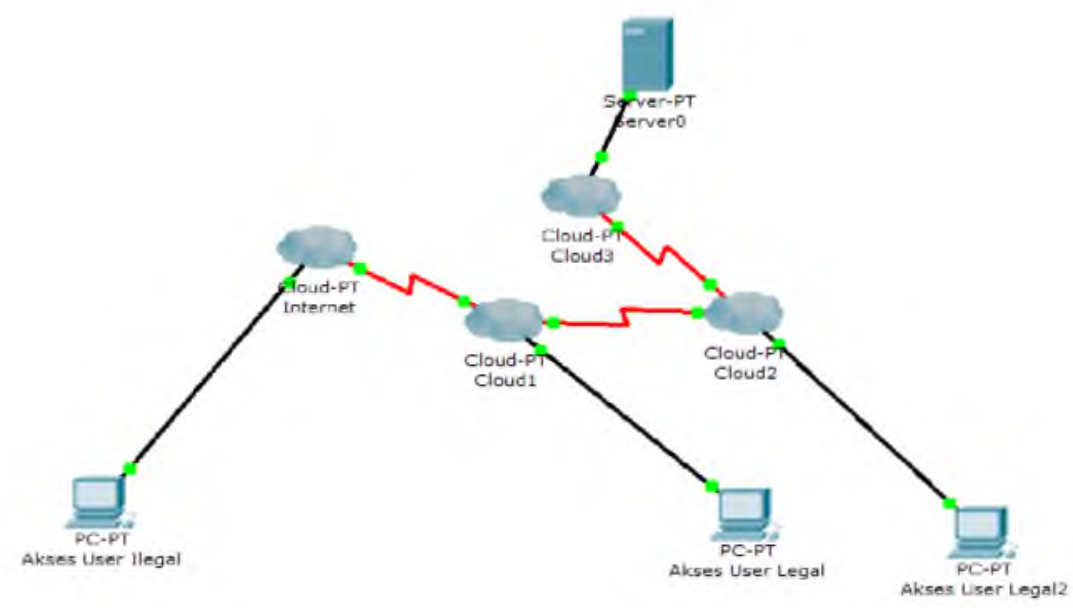

Gambar 1 Bagan Kegiatan.

Berdasarkan bagan kegiatan di atas, dapat dijelaskan bahwa kegiatan akses user ilegal dapat dilakukan dengan dengan menggunakan cara mengakses internet terlebih dahulu, dan mampu melakukan kegiatan yang semestinya tidak dapat diakses tersebut, dengan salah satu contohnya adalah dengan melakukan penetrasi password akses user legal. Tidak hanya penetrasi password kepada akses user legal saja, namun dapat melakukan penetrasi password terhadap server dan dapat me-remote access dari berbeda tempat.

\subsection{Diagram Konteks}

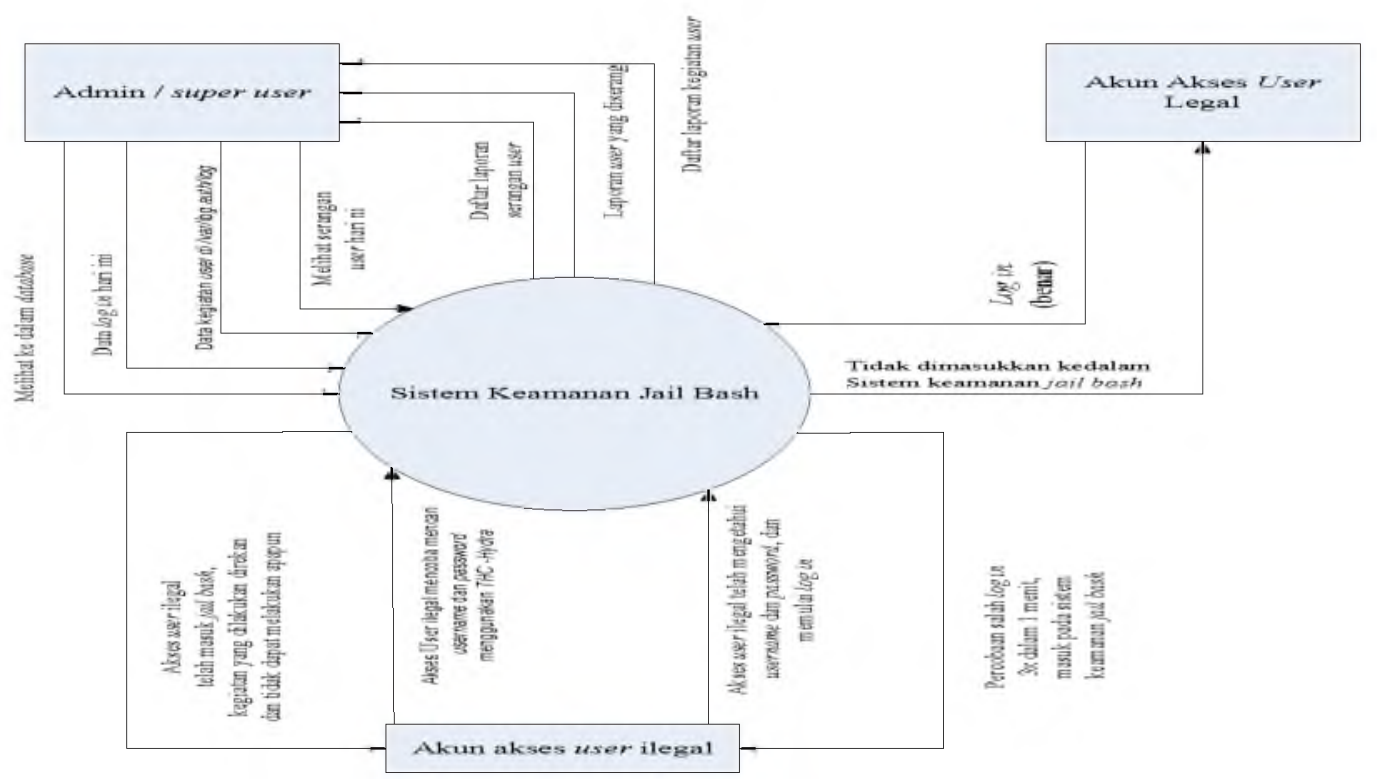

Gambar 2 Diagram Konteks.

Diagram konteks diatas, menjelaskan bahwa administrator/super user dapat mengakses kepada sistem keamanan yang dinamai jail bash. Sistem keamanan jail bash ini akan mengamankan akun yang ada pada sistem tersebut. Akses user ilegal melakukan kegiatan penetrasi password kepada akun yang dimiliki oleh akses user 
legal. Saat terjadi kegiatan penetrasi tersebut menggunakan aplikasi THC-Hydra, maka serangan tersebut akan terus menerus. Kegiatan terus menerus untuk mengetahui password tersebut, terdeteksi oleh sistem dan akan secara otomatisasi memasukkan akses $u$ ser ilegal kedalam sistem keamanan jail bash tersebut.

\subsection{Data Flow Diagram (DFD)}

Dapat dijelaskan bahwa administrator dapat melakukan dan mengetahui apapun yang dilakukan oleh akses user legal dan akses user ilegal. Akses user legal apabila akunnya telah dipenetrasi oleh akses user ilegal, maka akunnya pun akan terjebak dalam sistem jail bash, namun dapat dilakukan sistem recovery yang secara otomatisasi yang telah dibuat oleh administrator, dengan beberapa kriteria dan peraturan yang berlaku. Namun bagi akses user ilegal, untuk mendapatkan username dan password akun akses legal menggunakan aplikasi tambahan yaitu THC-Hydra, setelah hydra tersebut telah dapat mengetahui username dan password tersebut, maka langkah selanjutnya adalah sistem akan memasukkan akun yang dipenetrasi kedalam sistem jail bash untuk mengamankan data akun yang telah dipenetrasi.

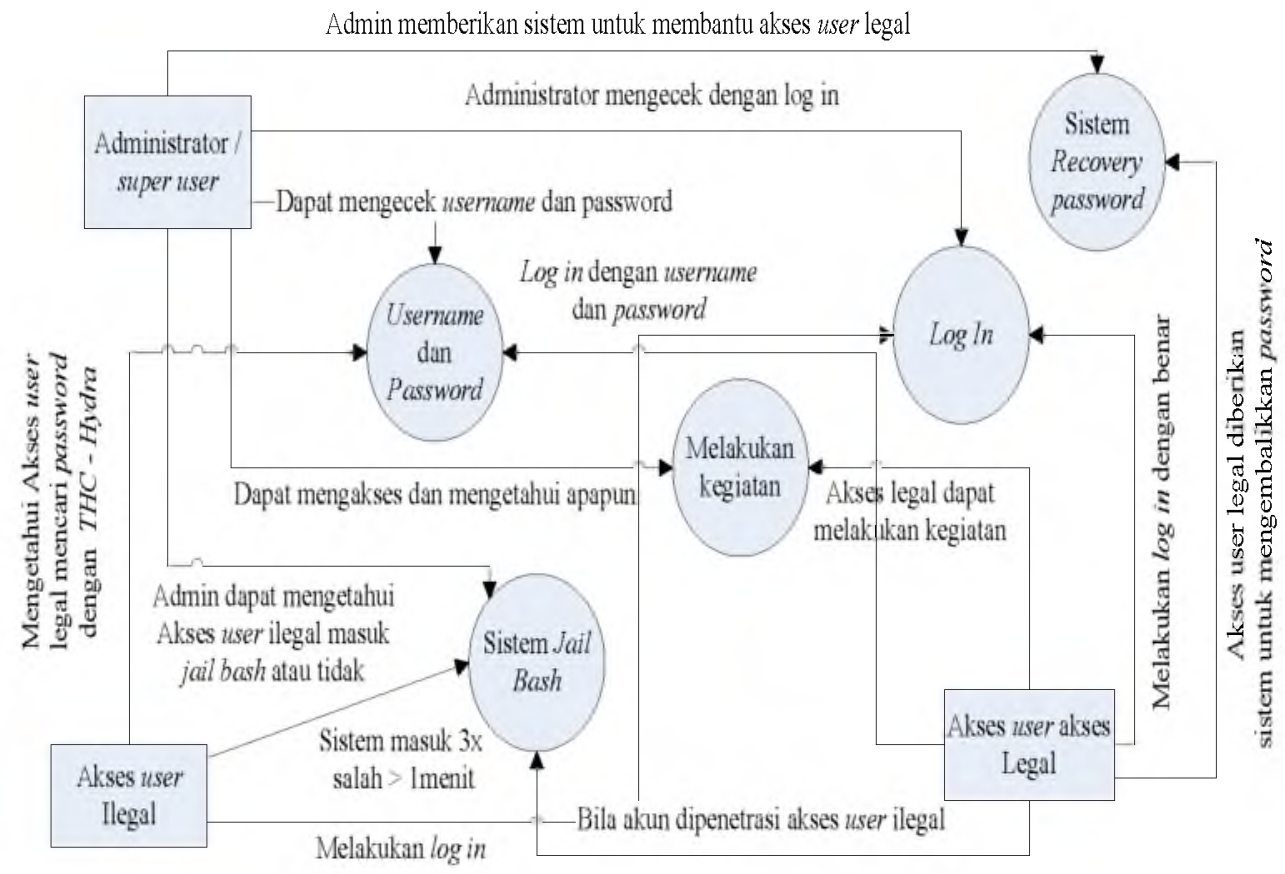

Gambar 3 DFD sistem kerja aplikasi

\subsection{Squirrelmail}

Squirrelmail adalah salah satu aplikasi web yang sudah terpasang di CPanel untuk keperluan membaca email. Squirrelmail adalah aplikasi webmail yang mendukung protokol IMAP dan SMTP dan menampilkan halaman dalam format HTML tanpa membutuhkan javascript, sehingga bisa dengan mudah diakses menggunakan browser apapun dan sangat ringan. Squirrelmail sendiri disini digunakan untuk proses recovery data dan password akun akses legal. Didalamnya terdapat akses link yang mengharuskan akses legal untuk mengganti password tersebut dan secara otomatisasi, sistem akan mendeteksi bahwa akun akses legal tersebut dapat 
melakukan aktifitas secara normal kembali dan tidak terpenjara dalam sistem jail bash.

\section{Hasil dan Pembahasan}

\subsection{Konfigurasi Aplikasi}

Crontab adalah sebuah perangkat lunak yang berguna untuk penjadwalan proses yang akan di eksekusi, crontab berjalan dibalik layar (daemon) yang terdapat pada sebuah sistem operasi linux. Hal ini memungkinkah penggunauntuk melakukan eksekusi aplikasi atau skrip program sesuai dengan waktu yang telah ditentukan. Cron dikendalikan oleh crontab (tabel cron) file, sebuah file konfigurasi yang menentukan perintah shell untuk menjalankan secara berkala pada jadwal yang diberikan. Dalam penulisan crontab terdapat format untuk melakukan penjadwalan menunjukkan bagian-bagian format penjadwalan yang disediakan.

\subsection{Uji Coba}

Uji coba jail bash ini dilakukan dan diletakkan pada sebuah web serverDigital Ocean. Pengujian dilakukan dengan 11 kali, yaitu dengan akses user legal sebanyak 10 kali, akses user ilegal sekali. Pengujian ini dapat dilakukan dibanyak akses perangkat komputer dimanapun, dengan menggunakan ssh. Berikut skema pengujian yang dilakukan.

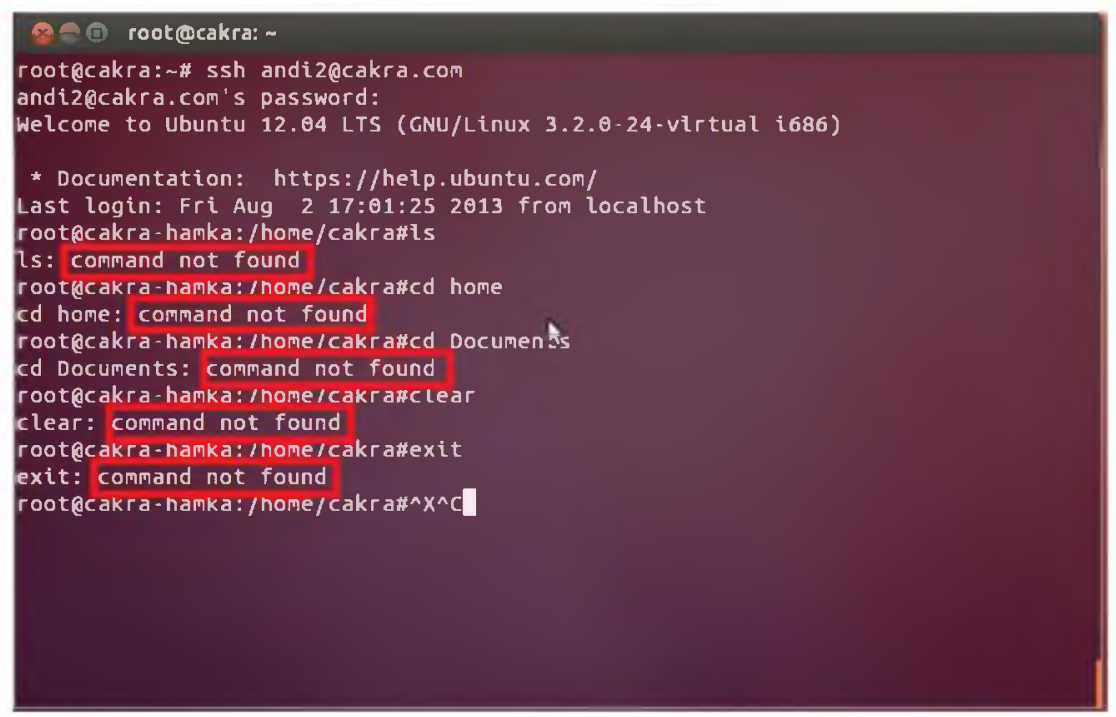

Gambar 4 kegagalan kegiatan akses user legal pada terminal.

Apabila saat akses user legal masuk dalam terminal, maka akan terjebak pula dalam shell penjara, dan tidak dapat melakukan apapun dalam terminalnya. 


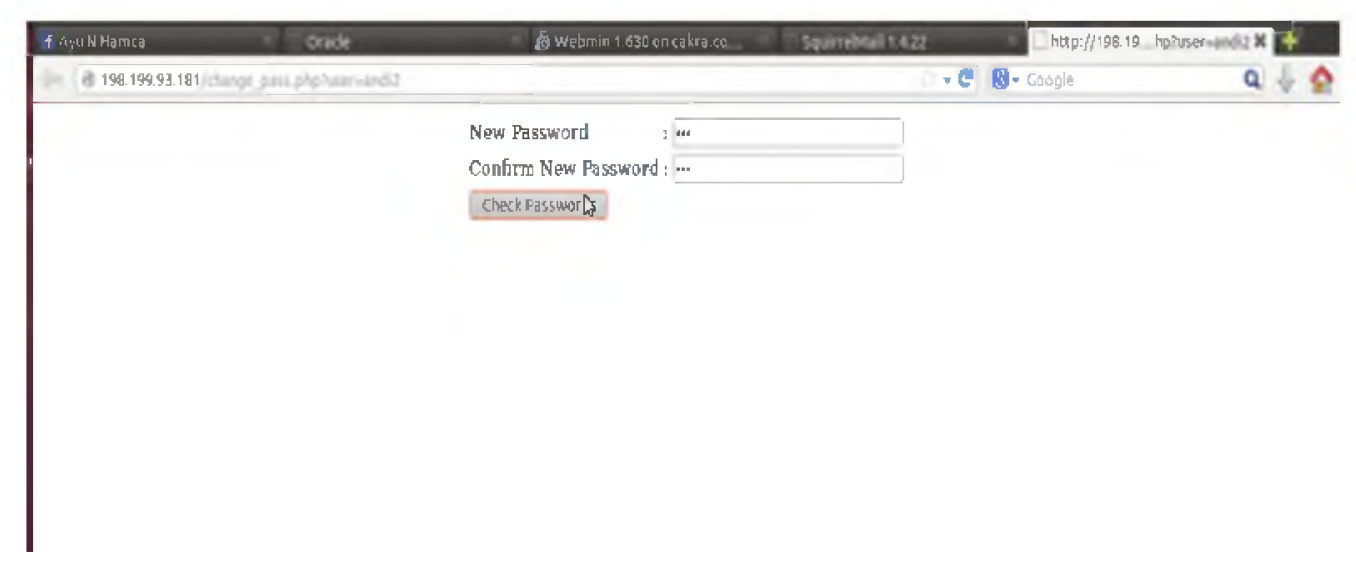

Gambar 5 Proses recoverypassword yang baru.

Namun dalam konteks disini, akses user legal telah dikirimkan oleh administrator sebuah email yang berisi perintah dan link untuk mengganti password yang baru. Link ini otomatis akan terkirim dan akses user legal dapat langsung mengganti password dengan ketentuan yang telah diberlakukan oleh administrator.

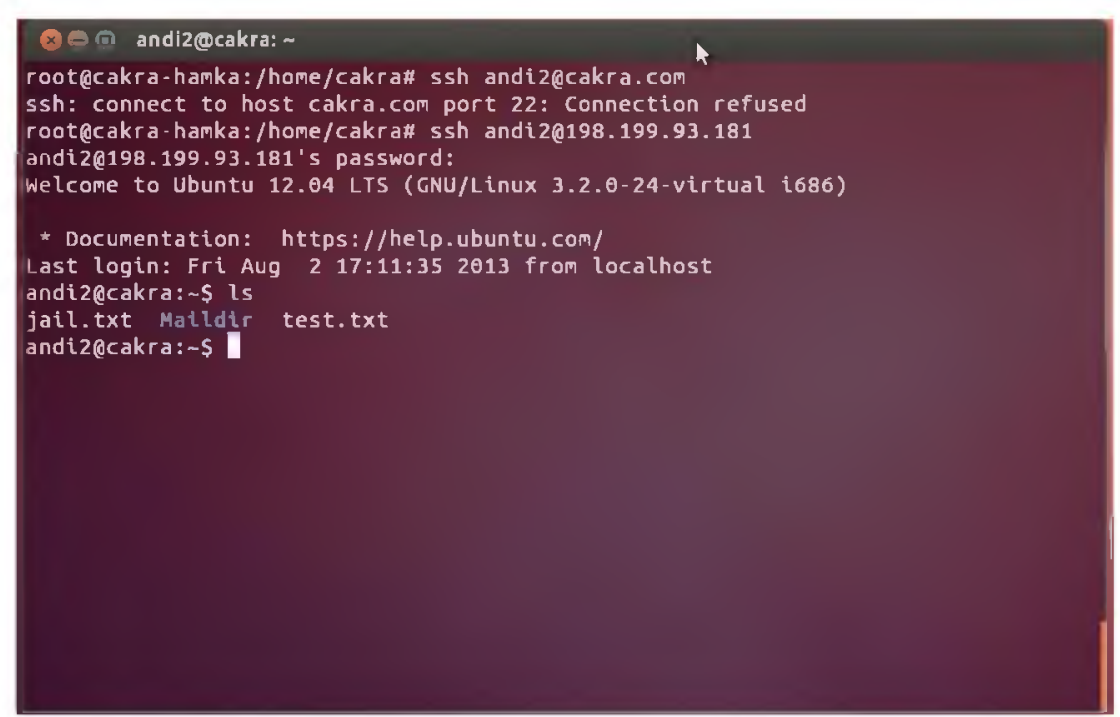

Gambar 6 Akses $u$ ser legal dapat melakukan aktifitas normal.

Setelah kembali lagi pada dan telah recovery password, ini menunjukkan bahwa shell andi2 telah dapat digunakan seperti biasanya, dan tidak terjebak pada shell penjara seperti sebelumnya, dan kegiatan seperti ls (list) telah dapat diakses seperti sebelumnya. 


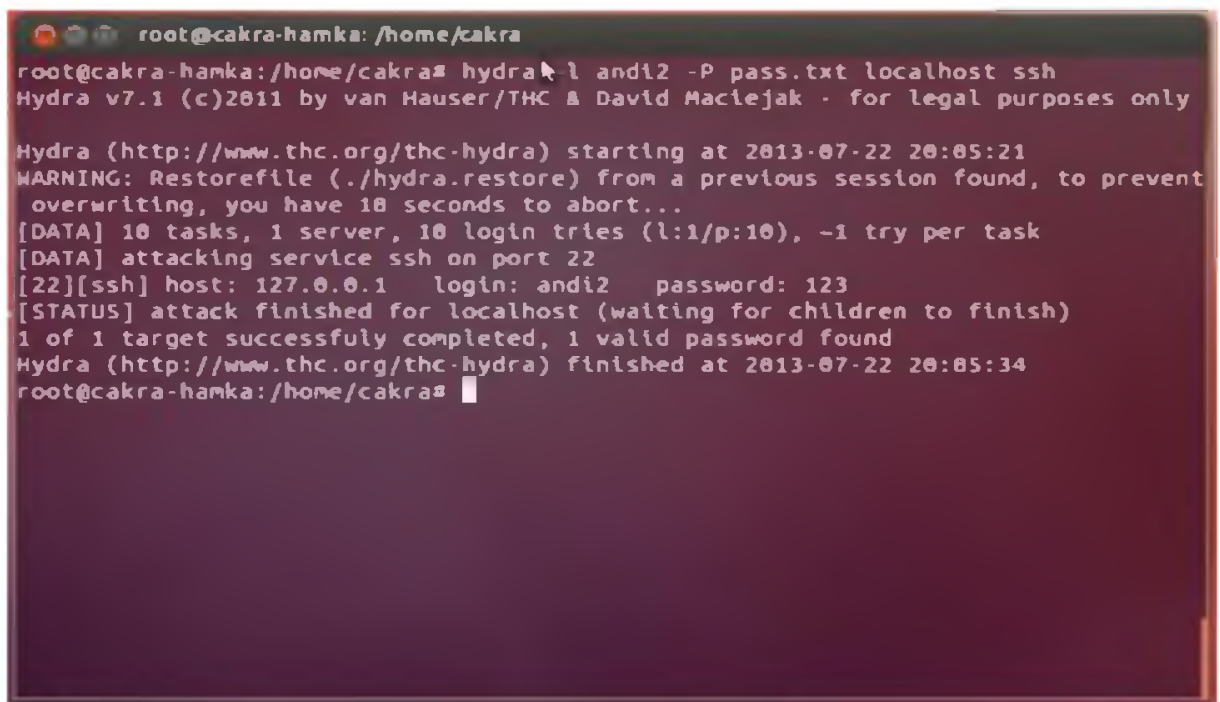

Gambar 7 Penetrasi dan aktifitas THC-Hydra oleh akses user ilegal mencari password.

Akses user ilegal adalah user yang tidak memiliki hak akses terhadap layanan $s$ sh, maka akses user illegal harus mengetahui username dan password tersebut, tentu pasti tanpa sepengetahuan dan dengan cara tidak lazim, yaitu dengan mencari-cari password tersebut dan mencoba-coba hingga benar. Biasanya akses user ilegal melakukan penyerangan terhadap akun akses user legal dengan menggunakan THCHydra.

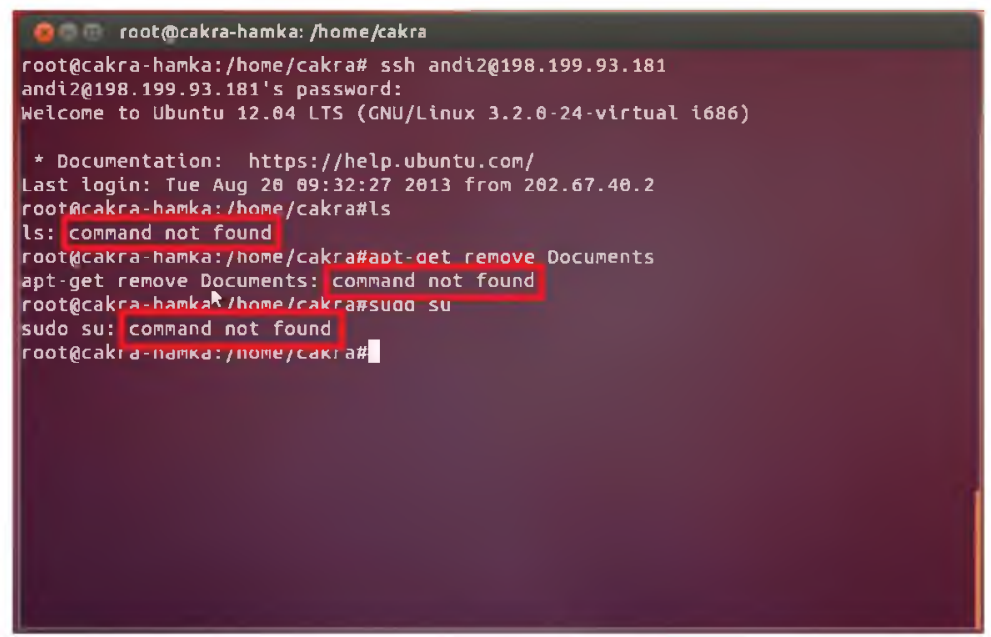

Gambar 8 Kegiatan akses user ilegal.

Akses user ilegal dapat masuk dalam shell penjara dikarenakan menggunakan sebuah aplikasi Hydra, konsep Hydra dengan mencoba terus menerus hingga ditemukannya password yang cocok, maka dengan demikian administrator dapat melakukan sebuah kondisi yang apabila terjadi kesalahan lebih dari 3 dalam 1 menit, maka aktifitas apapun di terminal tidak akan dapat terlaksana, dan aktifitas pun akan disimpan dengan sebuah file jail.txt. 


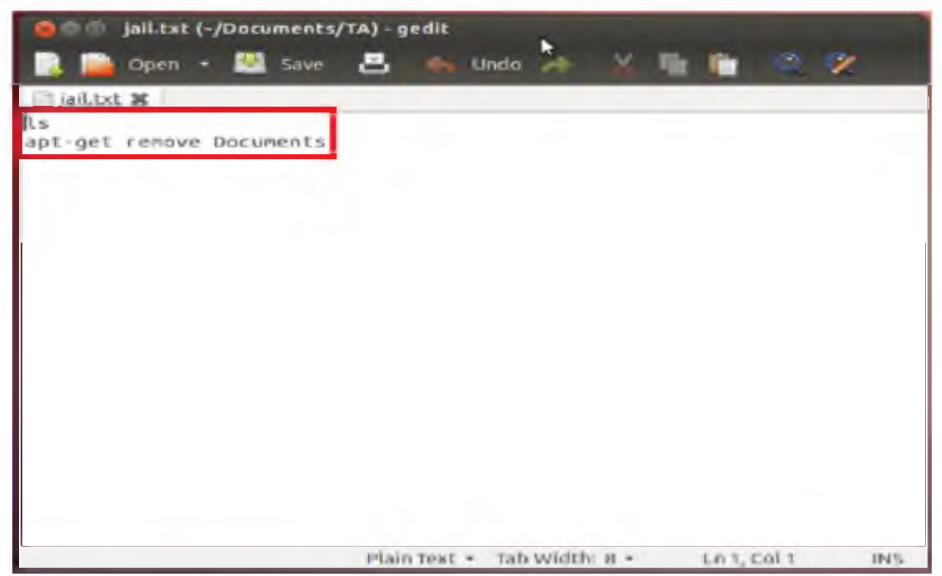

Gambar 9 Hasil pencatatan dari jail bash.

\section{Kesimpulan Dan Saran}

Kesimpulan yang diperoleh dari uji coba dan analisis adalah sebagai berikut:

1. Penerapan dalam shelljail telah dapat berfungsi secara otomatisasi dalam memenjarakan akses user ilegal dengan penerapan aturan yang di buat administrator.

2. Selain system dapat melindungi dirinya secara otomatis dan system juga dapat dan berhasil merekam (login) aktifitas akses user ilegal dalam bentuk apapun yang dilakukan oleh akses user ilegal di dalam shell penjara.

3. Proses recovery terhadap akses user legal telah berhasil dilakukan, melalui email yang telah dibuat dan dikirim oleh administrator.

Dari hasil perancangan dan pengujian yang dilakukan dapat diberikan saran untuk pengembangan selanjutnya, antara lain :

1. Aplikasi ini berbasis semi otomatis, dikarenakan pemicu pertahanan dari akses user ilegal ke dalam jail dari hasil kegiatan dan kejadian pada /oar/log/auth.log, bukan berbabasis pola waktu (realtime) pada saat akses user ilegal sedang melakukan aksi penetrasi.

2. Aplikasi ini dapat dikembangkan dengan beberapa komputer yang banyak dan saling berhubungan satu dengan yang lainnya dan dengan beberapa jenis serangan yang lebih banyak digunakan oleh akses user ilegal.

3. Sistem yang dibangun masih berdasarkan pemicu waktu, yaitu 1 menit sekali, sehingga sistem pertahanan dapat dikembangkan berdasarkan pemicu kejadian penyerangan.

\section{Daftar Pustaka}

Susanto, Budi. 2004, Pemrograman Script pada UNIX / LINUX, edisi pertama. Yogyakarta. Penerbit Graha Ilmu.

Mahardika, Irfan. 2003. Secure Remote Login Pada Sistem Operasi Slackware Linux. Semarang. Universitas Diponegoro Semarang.

Mubarok, M.Husna dan dan Yoyok Bagiyo 2007. Pemrograman Port Paralel dengan GCC/Linux dan Gambas/M.Husna Mubarok, hal 37.

Nugroho, Bunafit. 2005. Instalasi dan Konfigurasi Jaringan Windows dan Linux, edisi pertama, Yogyakarta. Penerbit Andi, hal,211.

Samsyiar, Evara. 2006. Belajar Sendiri Administrasi Database Oracle 10g. Jakarta: Penerbit PT Elex Media komputindo, halaman 34. 
Syafii, M. 2004, Konfigurasi Server Linux dengan Webmin. Yogyakarta: Penerbit Andi.

MADCOMS. 2004. Aplikasi Program PHP dan MySQL untuk membuat Website Interaktif. Yogyakarta :Penerbit Andi.

http://www.thc.org/thc-hydraj, diakses pada tanggal 5 Juli 2013. 
